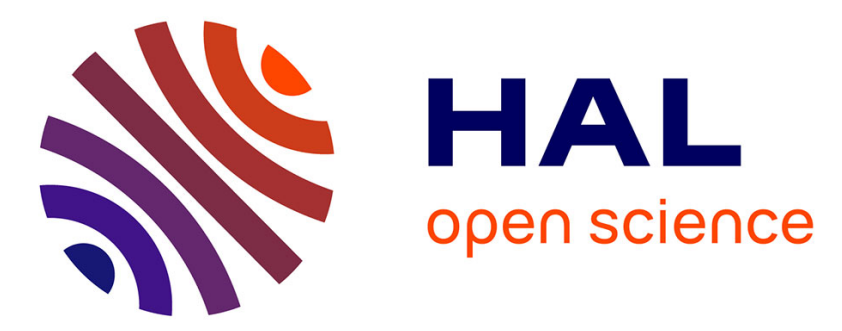

\title{
Usage-driven problem design for radical innovation in healthcare
}

\author{
Guillaume Lamé, Bernard Yannou, François Cluzel
}

\section{To cite this version:}

Guillaume Lamé, Bernard Yannou, François Cluzel. Usage-driven problem design for radical innovation in healthcare. BMJ Innovations, 2018, 4 (1), pp.15-23. 10.1136/bmjinnov-2016-000149 . hal-01648438

\section{HAL Id: hal-01648438 \\ https://hal.science/hal-01648438}

Submitted on 26 Nov 2017

HAL is a multi-disciplinary open access archive for the deposit and dissemination of scientific research documents, whether they are published or not. The documents may come from teaching and research institutions in France or abroad, or from public or private research centers.
L'archive ouverte pluridisciplinaire HAL, est destinée au dépôt et à la diffusion de documents scientifiques de niveau recherche, publiés ou non, émanant des établissements d'enseignement et de recherche français ou étrangers, des laboratoires publics ou privés. 


\title{
Usage-Driven Problem Design for Radical Innovation in Healthcare
}

\author{
Guillaume Lamé*, Bernard Yannou and François Cluzel \\ Laboratoire Genie Industriel, CentraleSupélec, Universite Paris-Saclay \\ Bâtiment Bouygues, 9 ter rue Joliot Curie, 91190 Gif-sur-Yvette, France;
}

\begin{abstract}
Whilst the diffusion and evaluation of healthcare innovations receive a lot of attention, the early design stages are less studied and potential innovators lack methods to identify where new innovations are necessary and to propose concepts relevant to users. To change this, we propose a structured methodology, Radical Innovation Design ${ }^{\circledR}$ (RID), which supports designers who want to work on the unstated needs of potential end-users in order to create superior value. In this article, the first part of RID is introduced with its two sub-processes: Problem Design and Knowledge Design. In this first period, RID guides innovators to systematically explore users' problems and evaluate which ones are most pressing in terms of innovation, taking into account existing solutions. The result is an ambition perimeter, composed of a set of value buckets, i.e. important usage situations where major problems are experienced and the current solutions provide little or no relief. The methodology then moves on to Solution Design and Business Design (which are not detailed in this paper) to address the value buckets identified.

With its emphasis on problem exploration, RID differs from methods based on early prototyping. The RID methodology has been validated in various industrial sectors, and is welladapted for healthcare innovation. To exemplify the methodology, we present a case study in dental imagery performed by ten students in 8 weeks. This example demonstrates how RID favors efficiency in Problem Design and allows designers to explore unaddressed and sometimes undeclared user needs.
\end{abstract}

\section{KEYWORDS}

Innovation methodology; Problem definition; Value bucket; Front end of innovation; Need-seeker innovation. 
Lamé, Guillaume, Bernard Yannou, and François Cluzel. 2017. "Usage-driven problem design for radical innovation in healthcare." BMJ Innovations (in press). doi: 10.1136/bmjinnov-2016-000149.

\section{INTRODUCTION}

Innovation is today a key concept in healthcare ${ }^{1}$ to manage increasing costs and constrained public spending and to exploit the full potential of new technologies. Although some may see it as a buzzword, innovation is here to stay, because innovation engineering and management allow more efficient development of useful concepts. ${ }^{2}$

Today, research on healthcare innovation mostly focuses on the diffusion ${ }^{3-6}$ and evaluation ${ }^{1,7,8}$ of innovations. However, before that, innovations must be designed to answer real, unmet needs. ${ }^{9-12}$ Medical professionals are not sufficiently prepared for post-design stages: legal requirements, production and distribution of the product. ${ }^{13}$ We argue that the same is true for design stages and primary problem formulation. Not all ideas have potential, and investing in low-potential ideas is a waste.

Designing radically innovative products that offer superior value is too often seen as a craft, an art for creative minds full of brilliant ideas. Methods for identifying important problems is a major, under-addressed challenge, whilst initial design phases are critical. ${ }^{14}$ The systematic development of value-creating artefacts must be studied scientifically. ${ }^{15}$ To do this, design science $^{16,17}$ must complement evaluative and explanatory research approaches. ${ }^{9,10}$

In this article, we introduce a method for designing innovative products and services, Radical Innovation Design ${ }^{\circledR}$ (RID). We focus on the first period of RID, made of the Problem Design and Knowledge Design sub-processes. We describe the RID process and show how RID is complementary to existing innovation methodologies. We then describe an example of application. Finally, we discuss the advantages of RID and the limitations of the study, and conclude on some perspectives for future research.

\section{LITERATURE REVIEW: INNOVATION METHODS}

Classical design processes are not adequate for innovative projects. ${ }^{18,19}$ They rely too much on combinations of existing elements at the expense of generating new concepts through new 
knowledge. Most methods focus on technical products at the expense of services. Finally, classic design theory starts from eliciting clearly requirements, which is impossible in innovative design where the need itself is unknown. When it comes to design processes in the healthcare sector, the design approach for healthcare services is weak, ${ }^{20}$ and there is a lack of comprehensive approaches to innovate on biomedical devices. ${ }^{21}$

Beyond healthcare, a few methods exist to support the first stages of innovative design projects. The most famous are Blue Ocean Strategy, ${ }^{22}$ Design Thinking ${ }^{23}$ and TRIZ. ${ }^{24}$ Blue Ocean Strategy is a marketing approach to identify unaddressed needs and "invent" new markets, but lacks engineering to qualify and categorize needs and concepts. Design Thinking is a set of principles, which relies on ethnographic observation for eliciting user needs and early and frequent prototyping. However, prototyping is sometimes too costly. Moreover, Design Thinking remains vague on how to process information to identify interesting ideas: it relies on the insight of the designer. TRIZ is an efficient method for creative problem solving, but it lacks user and market perspectives, and it focuses on technical innovation, not service or organizational innovations.

In the healthcare sector, wider innovation methods have been translated into sector-specific guidelines. ${ }^{9,25}$ The Biodesign approach, derived from Design Thinking, starts from the identification of users' needs, ranks them, and supports concept generation. ${ }^{10}$ However, it seems focused on biomedical devices, at the expense of services. In the methods proposed in the literature, some remain evasive on how to identify customer needs, ${ }^{26}$ other approaches do not specify how designers should choose which needs to investigate further. ${ }^{25}$ Finally, some methods seem to focus more on development than on the front-end of innovation. ${ }^{27}$ Some studies also describe current practice, but they do not provide advice for selecting innovative projects. $^{28,29}$ 
A new approach should keep these strengths and address these limitations: focus on users and their problems, explore unaddressed needs and create new markets, propose a clear process for knowledge gathering and analysis, provide tools for identifying promising areas, not restrict itself to products, and limit prototyping whenever possible. Moreover, given the specificity of the healthcare sector, ${ }^{30}$ the complex network of stakeholders and value expectations ${ }^{31}$ and the development of intermediate systems that participate to health but are not medical products per $s e$, this method should allow non-specialists to identify, gather and process relevant knowledge quickly.

\section{THE RADICAL INNOVATION DESIGN METHODOLOGY}

RID is a stage-gate, ${ }^{32}$ needs-based, ${ }^{9}$ structured methodology. RID is based on the idea that when designing innovative experiences, products and services, one should begin with the problems users encounter and what they seek to achieve, rather than focusing on products or technologies. ${ }^{33}$ This principle is referred to as "need-seeker innovation". ${ }^{34}$ Need-seeking innovators work hard "to find the unstated customer needs of the future, and to be the first to address them". ${ }^{34}$ It is the model of successful companies such as Apple, Tesla or Dyson, and a key notion for achieving radical innovation. ${ }^{35,36}$ To do so, RID supports the systematic modelling of classes of usage situations, classes of problems/pains and classes of existing solutions.

As illustrated in Figure 1, RID studies are divided into two periods. The first period corresponds to the preliminary stages of a radical innovation process where the problem is generally ill posed; in the literature, this is referred to as the fuzzy front end of innovation. In this first period (left of Figure 1), two sub-processes named Knowledge Design and Problem Design lead to an ambition perimeter, a type of marketing brief that contains the promise of addressing problems that are certainly worth addressing for users. From there start two sub-processes named Solution Design and Business Design. In this article, we focus on the first period: Problem Design and 

in healthcare." BMJ Innovations (in press). doi: 10.1136/bmjinnov-2016-000149.

Knowledge Design. Unlike those who advocate for prototyping as early as possible, ${ }^{2}$ in RID Problem Design and Solution Design are separate. Much effort goes on designing a problem whose solutions would create maximal value. We now detail the process of Problem Design (Figure 2).

As depicted in Figure 2, a RID project as every innovation project starts with an initial idea: sometimes a poorly justified pre-concept, more often a feeling that something needs to be done in a certain situation. Typical initial ideas already contain elements of solution: "this process/service/product needs to be lighter/more powerful/quicker". In RID this idea is reframed into an ideal goal within an activity field to reflect better the pains to eliminate or alleviate during a category of users activity instead of prescribing solution principles. For instance, the goal of dental imagery is not neater images, but to detect all the anomalies in patients' oral system as early as possible and to anticipate the medical process. Neater images are one way to do it, but this would exclude many potential solutions and restrain the design space.

From an ideal goal, RID explores pains/problems and usage situations using two tools:

- Pains / problems: causality graphs illustrate how problems relate to one another. Causality graphs are a classical tool to represent interdependencies between concepts, for instance in system dynamics modelling. ${ }^{37}$

- Usages: a usage is a situation happening when a type of user encounters a type of environment. ${ }^{38}$ It describes the actual way people act in given situations and which pains they experience. Information is collected using different methods: typically, interviews and observation to construct scenarios, and survey or literature review to quantify them. Scenarios are narratives depicting usages. They can be written stories or, better, short movies or storyboards. They are a communication tool. 
Lamé, Guillaume, Bernard Yannou, and François Cluzel. 2017. "Usage-driven problem design for radical innovation in healthcare." BMJ Innovations (in press). doi: 10.1136/bmjinnov-2016-000149.

- An additional dimension is how existing solutions apply to situations and how they solve problems. ${ }^{38}$ For example, in dental hygiene, "dental flush" and "mouthwash" do not address the same issues. Mouthwash prevents infections, but will not prevent food from being stuck between the teeth. Dental flush is useless against infections, but efficient to remove food from interdental spaces.

These three dimensions are then mapped one to one, which provides a model of how existing solutions apply to pains and usages (coverage and efficiency of existing solutions), and which pains arise in which situations (occurrence of pains). This information is aggregated in three matrices that cross problems with solutions, usage situations with problems, and usage situations with solutions. Usage situations and problems are weighted based on their frequency and severity/importance, most often using qualitative scales that are defined according to the topic being studied.

The three matrices and the weighs are processed using the DSM Value Bucket tool (Figure 3). ${ }^{39}$ Through matrix computation, the DSM Value Bucket tool eliminates the dimension of existing solutions to only show how pains and usages are currently covered, based also on their frequency and severity. At the end of the computation, each (pain, usage) pair is rated based on the value that remains to be created to alleviate user pains in this situation. Hence, designers can focus on the most important pains and usages.

The output of this process is a set of value buckets, i.e. instances where the gap is greatest between the ideal situation, where all pains are alleviated, and the current situation, where solutions only partly alleviate pains. Based on this information ("what is rationally good for people"), a consumer survey is conducted using Kano analysis ${ }^{40}$ to make sure that the identified value buckets are actually desired by customers ("what people want"). A coherent subset of value buckets that are both scored high in the DSM Value Bucket analysis and desired by customers in the Kano analysis is selected. These value buckets constitute the ambition 
Lamé, Guillaume, Bernard Yannou, and François Cluzel. 2017. "Usage-driven problem design for radical innovation in healthcare." BMJ Innovations (in press). doi: 10.1136/bmjinnov-2016-000149.

perimeter, i.e. the situations and problems that need to be addressed because they are the most promising for radical innovation in the particular context of the company (strategy, in-house knowledge and skills).

When the ambition perimeter is defined, the project can move to the second RID period made of Solution Design and Business Design sub-processes. It is important to note that up to this moment, there has been no "creativity session" customary to innovation methods for finding novel solutions, only brainstorming sessions for making sure that relevant knowledge is collected and that usage situations and existing solutions are documented. During the Problem Design phase, the project focuses on the pains of current users, not on solutions. The Knowledge Design process, where participants plan and carry their investigation, supports it. This problem setting method has now been applied in various sectors, with 42 projects since 2013, including eHealth and mHealth, mobile technology for the elderly, and adaptive tennis, along with other projects outside the healthcare sector. ${ }^{39,41-43}$ The feedbacks from industrial partners on these projects indicate that the method is perceived as effective and useful in identifying new development opportunities in a systematic way. These case studies are one way of validating a design method. ${ }^{44}$ Previous studies on RID also have shown that the quality of the problem setting phase greatly affects the quality of the final design, ${ }^{41,45}$ which supports the emphasis on and systematic approach to problem setting in RID.

To illustrate the application of RID in practice, we now present an example of a student project using RID. The purpose is to illustrate better the use of RID, rather than to validate its effectiveness.

\section{EXAMPLE IN DENTAL IMAGERY}

This project was carried out by ten students in $2015 .{ }^{46}$ Four held a BSc from a business school, the rest came from engineering curricula. Students had all enrolled in our Masters level course on radical innovation, in the engineering curriculum of a French engineering school (as there is 
Lamé, Guillaume, Bernard Yannou, and François Cluzel. 2017. "Usage-driven problem design for radical innovation in healthcare." BMJ Innovations (in press). doi: 10.1136/bmjinnov-2016-000149.

no medical curriculum in this school, we could not include medical students). The project lasted two months, with 18 hours of lectures on RID, 15 hours of lab classes, 120 hours dedicated to this project on the students' timetables and a final presentation in front of a panel of 25 innovation experts (both academic and professional). An industrial partner, Thales Microwave \& Imaging Sub-Systems, sponsored the project, and a teaching assistant (first author) and two teachers (second and third authors) supervised the participants.

The initial idea of the industrial sponsor was to revolutionize X-Ray imaging with miniaturized X-Ray sources they had developed. Most X-Ray sources on the market use the same technology since the 1930 's, but new techniques are emerging. ${ }^{47}$ The company wanted to identify business opportunities for this technology. To reduce the investigation (because of the time constraints of the course), the perimeter was restricted from medical imaging in general to dental imaging.

\section{Reframing the Initial Idea into the Ideal Goal}

The first step of the project was to transform a vague and techno-centered statement into a robust working perimeter. Students described their goal as a transfer function (transforming inputs into outputs, without describing the internal process), they identified stakeholders and beneficiaries and mapped the value chain in dental care. They came up with the following "Ideal goal":

"The purpose of our innovation is to evidence [any] oral cavity pathology at a possibly early stage and/or oral cavity treatment evolution, that cannot be seen by odontology professional upon anamnesis examination (analysis of the case history of the patient) and/or dental clinical examination, in order to diagnose and treat [all] pathology[ies] and/or to follow-up and adjust an undergoing treatment."

\section{Planning the Investigation}

With their Ideal goal defined, the students planned their investigation. They had little time for a complex project in a field they did not know. Therefore, an efficient knowledge investigation 
was necessary, and careful planning was paramount. The Knowledge Design process consists of a series of group brainstorming, ideas classification, filtering and a final investigation breakdown. For the project, this investigation breakdown consisted in four axis: the dental care process, dental pathologies and issues in diagnosis and treatment, existing solutions for dental diagnosis, and the typology of patients.

Participants used multiple data-collection methods: observations during dental consultations and interventions, interviews with dentists, odontologists and dentistry students; and research in the medical and technical (dental imagery, signal processing, etc.) literatures.

All the collected data was documented in "knowledge books". Knowledge books are documents from 5 to 20 pages that summarize knowledge on a particular subject relevant to the innovation project. These books contain references and literature analysis, images, interviews and observation data. They represent valuable knowledge that can be used at any time during the project, or for later projects, hence the need to write up and store all that information. The group produced books on the results of their interviews, the factors that influence oral health, tooth decay, pulpitis, periodontal diseases, oral cancer, radiographic methods and other tools for dental diagnosis.

The result of this investigation was the identification of archetypal usage situations, problems/pains and existing solutions (contributing to the ideal goal).

\section{Identifying Usage Situations}

In the case of dental care, usage situations describe dental pathologies, for certain populations whose diagnosis and/or treatment follows a certain course. The students analyzed eight situations:

- Early decay

- Advanced decay

- Gingivitis 
- Periodontitis

- Early oral cancer

- Advanced oral cancer

- Orofacial birth defect

- Oral trauma

Situations are described as usage scenarios. Scenarios are intersections between a typology of usage contexts and a typology of user profiles ${ }^{48}$. They can be described through different methods, e.g. storytelling, storyboarding, persona method. A piece of scenario designed with toondoo.com is presented in Figure 4 for the non-detection of early decay. In this case, the scenario is rather simple, but such figurative representations facilitate communication and argumentation.

\section{Identifying Problems}

Problems, or pains, are events or factors that prevent situations from going in the desired direction and contribute to low or bad performances of the activity referred by the ideal goal here the practice of dental imaging -. Thus the pains must refer here to the dental imager, and not to patients. The methodology helped students to go deep into the following problems during their investigation:

- Cost: treatment or diagnosis is too expensive for the patient

- Sensitivity: the technique creates false positives

- Specificity: the technique generates false negatives

- Localization: the technique lacks precision to localize the issue

- Ability to precisely define a disease, e.g. the depth of a decay

- Ability to prepare treatment: the technique lacks precision to determine the stage of a disease

- Universality of the solution, e.g. X-rays are contraindicated for pregnant women. 
Lamé, Guillaume, Bernard Yannou, and François Cluzel. 2017. "Usage-driven problem design for radical innovation in healthcare." BMJ Innovations (in press). doi: 10.1136/bmjinnov-2016-000149.

\section{Documenting Existing Solutions}

The students needed to analyze all methods that could be used to fulfil their ideal goal. They asked dentists and searched the literature to identify those that are routinely used and some that are less common. They included case history, the visual-tactile method, electric conductance measurement, various imaging methods and biopsy. They read the technical specifications, the reimbursement schemes and the scientific evidence for these methods, in order to identify the contribution of each method to diagnosis and treatment.

\section{Deriving Value Buckets}

The investigation produced a lot of knowledge on usage situations, problems experienced by users and existing solutions. The challenge is to analyze this information in a way that allows to identify gaps, uncovered situations, or better said value buckets - important usage situations where major problems are experienced and the current solutions provide little or no relief.

To do this, the DSM Value Bucket algorithm ${ }^{39}$ maps usage situations, usage problems and existing solutions to each other. Through matrix calculations, it evidences the gap between the ideal performance, where all problems are solved in all situations, and the existing performance, to define value buckets.

Figure 3 shows the data flow in the algorithm (for a detailed theoretical presentation of the algorithm, see ${ }^{39}$ ). First, three matrices A, B and C are built that map domains to one another. They are filled based on expert opinion, using an ordinal scale: 0 . No/Never; 1 . Very few; 2 . A few/rarely; 3. Some/sometimes; and 4. Many/Often. Matrices B and C are multiplied to eliminate the "existing solutions" and come up with the part of problems that can theoretically be removed or lessened in average in the different usage situations, using existing solutions. Matrix D represents the difference between problems experienced in usage situations (matrix A) and the way existing solutions cover them (matrix $C^{*} B$ ). It is filtered to remove the lowest values. Because problems and usage situations are not all equivalent, they are weighted based 
Lamé, Guillaume, Bernard Yannou, and François Cluzel. 2017. "Usage-driven problem design for radical innovation in healthcare." BMJ Innovations (in press). doi: 10.1136/bmjinnov-2016-000149.

on their importance. The result is matrix E, shown in Figure 5. From these results, the most important areas for usage-driven innovation are the localization of early decay, the sensitivity to early oral cancer and the ability to assess periodontitis.

\section{Scoping the Ambition Perimeter}

To refine the analysis, and decide which value buckets to investigate further, two additional inputs are needed: the company's identity, and elements of market expectations. In this case, the company sees more potential in early decay diagnosis, as oral cancers develop in soft tissues and are therefore intractable by X-Rays without contrast products. To analyze market demand, RID uses Kano surveys, ${ }^{40}$ which define a model of a product's attributes. An online questionnaire was sent, and the six dentists who responded confirmed that detection of early decay and early cancer was a much-desired feature. More answers would have been desirable, but time was lacking. However, the survey continued to run after the end of the project. In this case, the validity of the Kano survey results is more comparable to that of a focus group than a full-scale survey.

Based on the results of the Kano survey and the company's position, the ambition perimeter a form of marketing brief to continue the project - was defined as improving the sensitivity of tools to, and their ability to localize, early decay.Having identified value buckets and accumulated knowledge on the professional practice of dentistry and the technical aspects of dental imagery, students defended this perimeter to their sponsors.

\section{Reception}

This work was evaluated very positively by a panel of experts (innovation consultants, innovation academics, industry representatives) using a validated framework for the evaluation of innovative projects. ${ }^{49,50}$ The fastness and relevance of the students to acquire specific technical knowledge and communicate it, and their capacity to reason from the multiple perspectives of different users were qualified as impressive by the 20-year experience chief 
Lamé, Guillaume, Bernard Yannou, and François Cluzel. 2017. "Usage-driven problem design for radical innovation in healthcare." BMJ Innovations (in press). doi: 10.1136/bmjinnov-2016-000149.

innovation officer who monitored the project. The industrial sponsor stated: "what quite amazed me ... is the quantity of information [generated and analyzed] in such a short time, during which a lot of things appear". He described the student as "non-specialists who, in a short time period, have almost become specialists".

\section{DISCUSSION}

In innovation projects, it is important to be at the same time fast and systematic in the exploration of the problem to be addressed. This example in dental imagery shows how quickly a group of non-specialists managed to convince an innovation manager by the way they had planned, collected and processed data to identify meaningful opportunities. Such case studies are an important means of validation in design research. ${ }^{44}$ In a corporate project, we would have included dentists and biomedical engineers in the process. As this was a student project, it was not possible to choose the participants, but we may suppose that participants with more prior knowledge of the topic would have gone quicker and further in their investigation.

The challenges in the application of RID depend largely on the context of application. In healthcare, two difficulties have been identified. First, it is hard to get physician input due to lack of time on their part or limited answers in surveys. Second, as in most healthcare design projects, involving patients can be challenging, both in terms of regulation of access and in ethical terms. There is no silver bullet to solve these challenges, and the adequate answers are context-bound.

The description of the RID process and the example illustrate how RID balances agility (it adapts to many sectors and accommodates all data collection methods) with a systematic exploration of the design space. The different tools in the method (causal maps, Kano survey, scenarios, and DSM Value Bucket tool) support the process and help designers to manage the data collection process. The tools and the process support informed decision-making at each 
stage, e.g. by ranking value buckets, or by constructing causality chains. RID also tackles both the product and service dimensions by analyzing in depth usage situations.

RID can be compared to other approaches that favor early prototyping. ${ }^{2}$ In dental imaging, the cost of functional prototypes is very high. Therefore, before having a good business case, prototyping is risky. It is thus crucial to have accumulated enough knowledge before prototyping, so that the confidence of tackling the right issue is already high. ${ }^{10}$

\section{Limitations}

This research has limitations. The example provided is a student project, so the context is different from that of corporate industrial projects. Other projects have been carried but cannot be discussed yet for confidentiality reasons. A comprehensive example on adaptive tennis is presented in ${ }^{39,43}$. Due to space limitations, we also only present the first stages of a design process, namely problem design. Finally, additional research is needed to support the claim that RID increases innovation success. To this date, partial validation elements have been provided on the form of case studies and experiments, e.g. in ${ }^{15,39,41,50}$.

\section{CONCLUSION}

In this article, we argued that problem design is a major, under-addressed challenge for innovators. To support this process, we introduced a methodology, RID, and its working concepts: value buckets, ambition perimeter, usage situations, problems/pains, and existing solutions. We then presented a case study, where 10 students, without any preexisting medical knowledge, managed in 8 weeks to carry out an investigation of innovations needed in dental imagery. Their findings would be more robust with more time and expertise, yet this example demonstrates how a structured method for problem design allowed to gather data quickly and to identify important, unanswered problems.

Future research should focus on the application and validation of the method on other problems in the healthcare sector, to increase confidence in its validity. ${ }^{44}$ The application of RID with 
Lamé, Guillaume, Bernard Yannou, and François Cluzel. 2017. "Usage-driven problem design for radical innovation in healthcare." BMJ Innovations (in press). doi: 10.1136/bmjinnov-2016-000149.

mixed groups of physicians, engineers and business developers is of particular interest. It could help develop training modules for healthcare professionals, who are currently usually not trained for innovation and entrepreneurship. ${ }^{13}$ Involving patients in projects is also an important perspective. Finally, a dedicated version of RID for healthcare could also be developed, with additional tools to support some specific sectorial aspects, in particular regulatory requirements. ${ }^{13,28,29}$ 


\section{ACKNOWLEDGEMENTS}

We thank our students, Pauline Casert, Gabriel Crocherie, Hamza El Abboubi, Marine Guigon, Louise Marc, Louis Piquard, Nina Rognon, Safouane Taqi, Zoé Terreaux, and Zhaohua Wu, and the industrial supervisor from Thales Microwave \& Imaging Sub-Systems, M. Michel Caplot.

\section{FUNDING}

The case study presented in this article was partly funded by Thales Microwave \& Imaging Sub-systems. However, all opinions expressed in the article remain the authors' and cannot be presumed to be endorsed by Thales Microwave \& Imaging Subsystems.

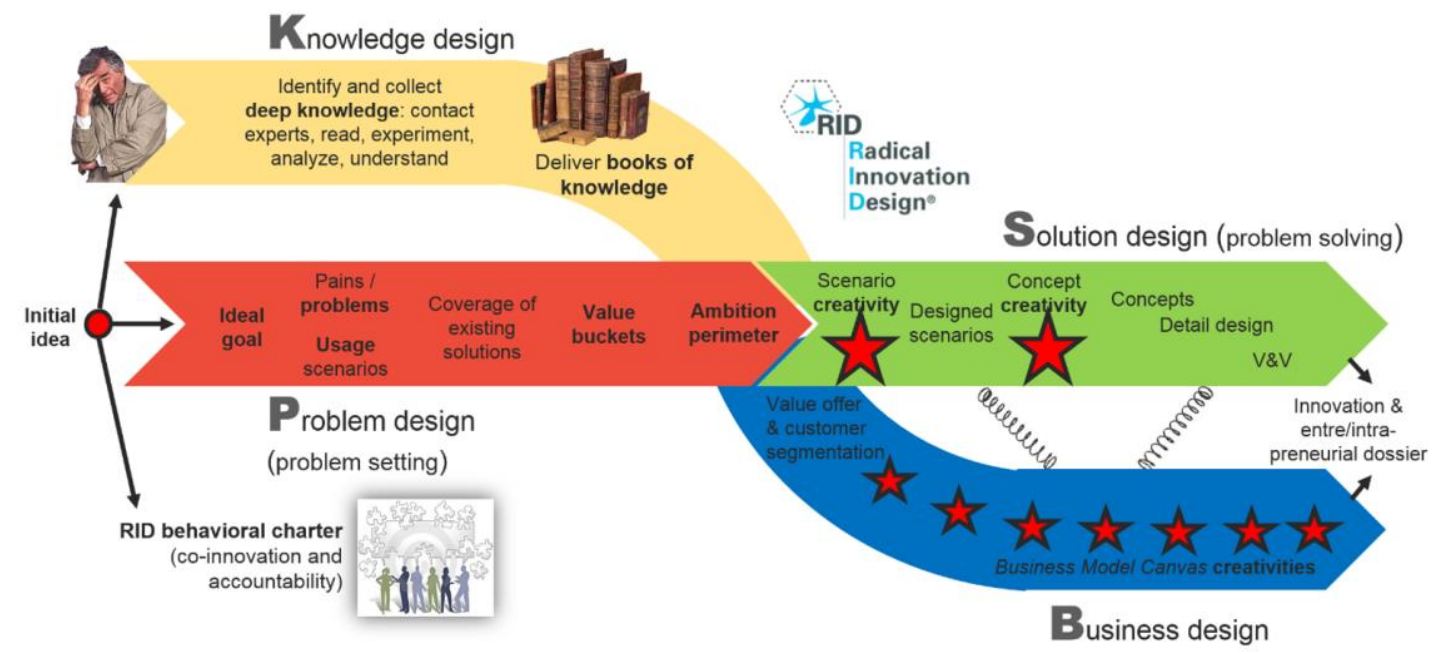

Figure 1 - The Radical Innovation Design process 
Lamé, Guillaume, Bernard Yannou, and François Cluzel. 2017. "Usage-driven problem design for radical innovation in healthcare." BMJ Innovations (in press). doi: 10.1136/bmjinnov-2016-000149.

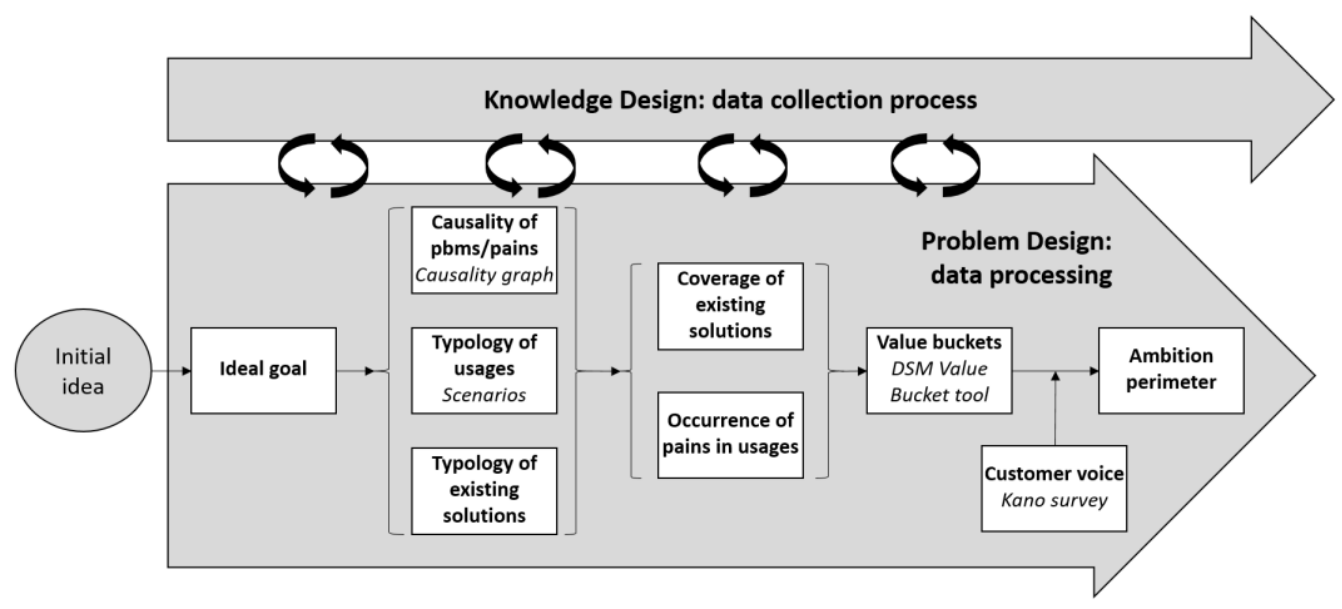

Figure 2 - The RID Problem Design process

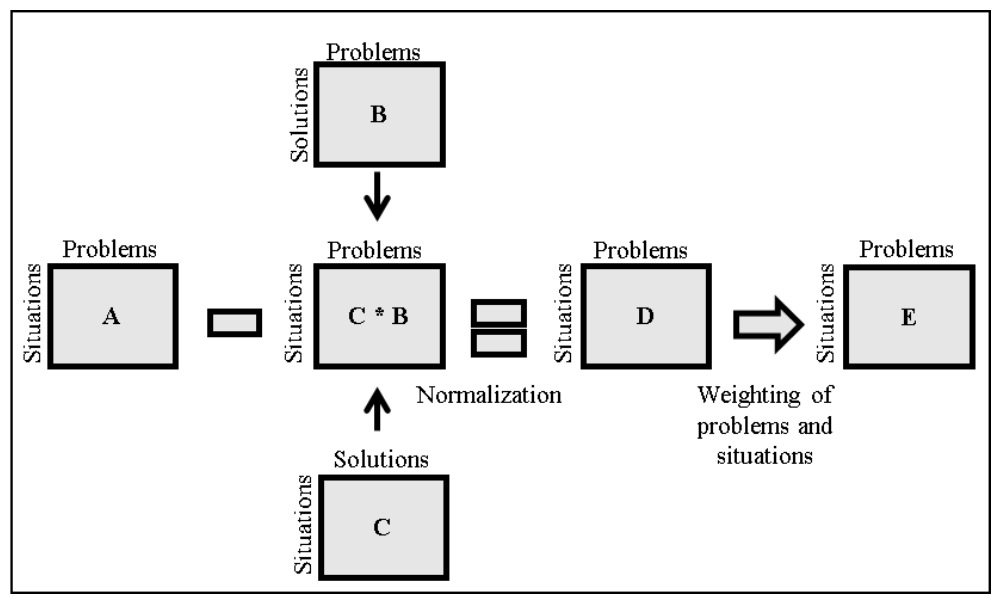

Figure 3 - Data flow of the DSM Value Bucket algorithm 

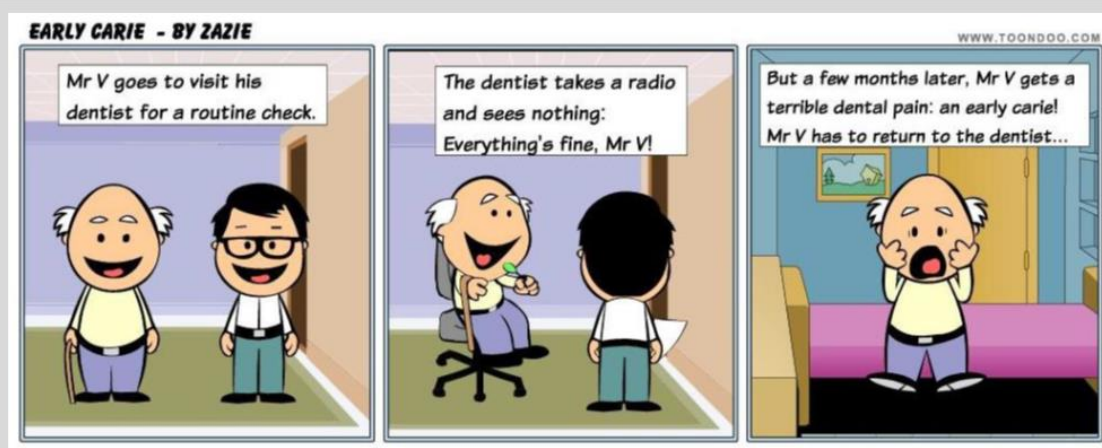

The patient visits the dentist for an annual check-up (he has no pain), the dentist performs anamnesis, clinical examination and panoramic radiography. With all these details, he cannot detect early tooth decay.

Few months later, the patient has a high pain in the same place where the early tooth decay was, he comes back to the dentist. The tooth decay is important, he has to remove the nerve from the tooth or to tear the tooth and to insert an implant (it takes lots of medical examination, it is expensive and it can be unaesthetic ...).

Figure 4 - Storyboard for non-detection of early decay

\begin{tabular}{|c|c|c|c|c|c|c|c|}
\hline$E$ & Cost & Sensibility & Specificity & Localization & $\begin{array}{c}\text { Ability to } \\
\text { differentiate the } \\
\text { sorts of diseases }\end{array}$ & $\begin{array}{l}\text { Ability to } \\
\text { prepare the } \\
\text { therapeutic } \\
\text { procedure }\end{array}$ & $\begin{array}{c}\text { Ability to apply } \\
\text { the solution on } \\
\text { all the } \\
\text { populations }\end{array}$ \\
\hline Early decay & 0 & 5.4 & 0 & 13.6 & 0 & 0 & 0 \\
\hline Advanced decay & 0 & $\sigma$ & 0 & 2.56 & 0 & 2.56 & 0 \\
\hline Gingivitis & 0 & 0 & 0 & 0 & 0 & 0.2 & 0 \\
\hline Periodontitis & 0.09 & 264 & 0 & 0 & 1.98 & 4.92 & 1.86 \\
\hline Early oral cancer & 3.18 & 5.68 & 2.40 & 5.6 & 308 & 5.28 & 1.64 \\
\hline Advanced oral cancer & 1.5 & $\overline{0.04}$ & 0.04 & 0 & $\theta$ & 3.04 & 0.8 \\
\hline Orofacial birth defect & 2.34 & 0 & 0.48/ & $\theta$ & 0.36 & 2.2 & 0.76 \\
\hline Oral trauma & 0.99 & 0 & 8 & 0 & 0.42 & 0.4 & 0.14 \\
\hline
\end{tabular}

Figure 5 - Matrix E (Value Buckets matrix) in the dental imagery project

\section{REFERENCES}

1. Varkey P, Horne A, Bennet KE. Innovation in Health Care: A Primer. Am J Med Qual. 2008 Sep 1;23(5):382-8.

2. Asch DA, Rosin R. Innovation as Discipline, Not Fad. N Engl J Med. 2015 Aug 13;373(7):592-4. 
3. Greenhalgh T, Robert G, Macfarlane F, Bate P, Kyriakidou O. Diffusion of Innovations in Service Organizations: Systematic Review and Recommendations. Milbank Q. 2004 Dec;82(4):581-629.

4. Oldenburg B, Glanz K. Diffusion of innovations. In: Glanz K, Rimer BK, Viswanath K, editors. Health Behavior and Health Education-Theory Research, and Practice. 4th ed. San Francisco, CA: Jossey-Bass; 2008. p. 313-30.

5. Williams I. Organizational readiness for innovation in health care: some lessons from the recent literature. Health Serv Manage Res. 2011 Nov 1;24(4):213-8.

6. Dixon-Woods M, Amalberti R, Goodman S, Bergman B, Glasziou P. Problems and promises of innovation: why healthcare needs to rethink its love/hate relationship with the new. BMJ Qual Saf. 2011 Apr 1;20(Suppl 1):i47-51.

7. Jönsson B. Ten arguments for a societal perspective in the economic evaluation of medical innovations. Eur J Health Econ. 2009;10(4):357-9.

8. Henshall C, Schuller T. Health Technology Assessment, Value-Based Decision Making, and Innovation. Int J Technol Assess Health Care. 2013 Oct;29(04):353-9.

9. Yock P. Needs-based innovation: the biodesign process. BMJ Innov. 2015 Jan;1(1):3-3.

10. Yock PG, Brinton TJ, Zenios SA. Teaching Biomedical Technology Innovation as a Discipline. Sci Transl Med. 2011 Jul 20;3(92):92cm18.

11. Sista AK, Hwang GL, Hovsepian DM, Sze DY, Kuo WT, Kothary N, et al. Applying a Structured Innovation Process to Interventional Radiology: A Single-Center Experience. J Vasc Interv Radiol. 2012 Apr;23(4):488-94.

12. Patel MI, Moore D, Blayney DW, Milstein A. Transforming Cancer Care: Are Transdisciplinary Approaches Using Design-Thinking, Engineering, and Business Methodologies Needed to Improve Value in Cancer Care Delivery? J Oncol Pract. 2014 Mar 1;10(2):e51-4.

13. Levy A, Coulthard M, Harvey M, Talbot S, Rich G. Tube Anchor: development of a small medical device from concept to market. BMJ Innov. 2015 Oct;1(4):151-6.

14. Lansisalmi H, Kivimäki M, Aalto P, Ruoranen R. Innovation in Healthcare: A Systematic Review of Recent Research. Nurs Sci Q. 2006 Jan 1;19(1):66-72.

15. Yannou B. Which research in design creativity and innovation? Let us not forget the reality of companies. Int J Des Creat Innov. 2013 Apr;1(2):72-92.

16. Cross N. Designerly Ways of Knowing: Design Discipline Versus Design Science. Des Issues. $2001 \mathrm{Jul} ; 17(3): 49-55$.

17. Papalambros PY, Ahmed-Kristensen S, Badke-Schaub P, Bauerly K, Boujut J-F, Cagan J, et al. Design Science: Why, What and How. Des Sci [Internet]. 2015 Jul [cited 2016 Feb 5];1. Available from: http://www.journals.cambridge.org/abstract_S2053470115000013 
18. Lenfle S, Le Masson P, Weil B. When Project Management Meets Design Theory: Revisiting the Manhattan and Polaris Projects to Characterize 'Radical Innovation' and its Managerial Implications. Creat Innov Manag. 2016 Sep;25(3):378-95.

19. Motte D, Yannou B, Bjärnemo R. The Specificities of Radical Innovation. In: Proceedings of the 3rd Internation Conference on Research into Design [Internet]. Bangalore, India: Research Publishing; 2011 [cited 2017 Mar 15]. p. 79-86. Available from: https://www.designsociety.org/download-

publication/32342/the_specificities_of_radical_innovation

20. Jun GT, Ward J, Clarkson PJ. Systems modelling approaches to the design of safe healthcare delivery: ease of use and usefulness perceived by healthcare workers. Ergonomics. $2010 \mathrm{Jul} ; 53(7): 829-47$.

21. Terziovski M, Morgan JP. Management practices and strategies to accelerate the innovation cycle in the biotechnology industry. Technovation. 2006 May;26(5-6):54552.

22. Kim WC, Mauborgne R. Blue ocean strategy: how to create uncontested market space and make the competition irrelevant. Expanded edition. Boston, Massachusetts: Harvard Business Review Press; 2015.

23. Brown T, Katz B. Change by design: how design thinking transforms organizations and inspires innovation. 1st ed. New York: Harper Business; 2009. 264 p.

24. Altshuller GS. Creativity as an exact science: the theory of the solution of inventive problems. New York: Gordon and Breach Science Publishers; 1984. 319 p. (Studies in cybernetics).

25. Durfee WK, Iazzo PA. Medical device innovation handbook. Minneapolis: University of Minnesota; 2016.

26. Canciglieri Junior O, Okumura MLM, Young RIM. The Application of an Integrated Product Development Process to the Design of Medical Equipment. In: Stjepandić J, Wognum N, J.C. Verhagen W, editors. Concurrent Engineering in the 21st Century [Internet]. Cham: Springer International Publishing; 2015 [cited 2017 Aug 29]. p. 73559. Available from: http://link.springer.com/10.1007/978-3-319-13776-6_25

27. Pietzsch JB, Shluzas LA, Paté-Cornell ME, Yock PG, Linehan JH. Stage-Gate Process for the Development of Medical Devices. J Med Devices. 2009;3(2):021004.

28. Medina LA, Kremer GEO, Wysk RA. Supporting medical device development: a standard product design process model. J Eng Des. 2013 Feb;24(2):83-119.

29. Santos IC, Gazelle GS, Rocha LA, Tavares JMR. Medical device specificities: opportunities for a dedicated product development methodology. Expert Rev Med Devices. 2012 May;9(3):299-311.

30. Herzlinger RE. Why innovation in health care is so hard. Harv Bus Rev. 2006;84(5):58.

31. Klein JH, Young T. Health care: a case of hypercomplexity? Health Syst. 2015 $\mathrm{Jul} ; 4(2): 104-10$. 
32. Mehta SS. Commercializing successful biomedical technologies: basic principles for the development of drugs, diagnostics and devices. Cambridge; New York: Cambridge University Press; 2008. 335 p.

33. Bettencourt LA, Brown SW, Sirianni NJ. The secret to true service innovation. Bus Horiz. 2013 Jan;56(1):13-22.

34. Jaruzelski B, Staack V, Goehle B. Proven paths to innovation success. Strategy Bus BoozCompany. 2014;

35. Christensen CM. The innovator's dilemma: when new technologies cause great firms to fail. Boston, MA: Harvard Business School Press; 1997. 252 p. (The management of innovation and change series).

36. Christensen CM, Raynor ME. The innovator's solution: creating and sustaining successful growth. Boston: Harvard Business School Press; 2003. 304 p.

37. Sterman JD. System Dynamics Modeling: Tools for Learning in a Complex World. Calif Manage Rev. 2001 Jul;43(4):8-25.

38. Bekhradi A, Yannou B, Farel R, Zimmer B, Chandra J. Usefulness Simulation of Design Concepts. J Mech Des. 2015 Jul 1;137(7):071412.

39. Yannou B, Cluzel F, Farel R. Capturing the relevant problems leading to pain- and usagedriven innovations: The Dependency Structure Modeling Value Bucket algorithm. Concurr Eng [Internet]. 2016 Oct 5; Available from: http://cer.sagepub.com/content/early/2016/10/05/1063293X16666311.abstract

40. Kano N, Seraku N, Takahashi F, Tsuji S. Attractive Quality and Must-Be Quality. J Jpn Soc Qual Control. 1984 avril;14(2):147-56.

41. Yannou B, Jankovic M, Leroy Y, Okudan Kremer GEO. Observations From Radical Innovation Projects Considering the Company Context. J Mech Des. 2013 Jan 7;135(2):021005 (17p).

42. Bekhradi A, Yannou B, Cluzel F, Vallette T. Categorizing user pains, usage situations and existing solutions in front end of innovation: The case of smart lighting project. In: Proceedings of the 21st International Conference on Engineering Design. Vancouver, BC, Canada: The Design Society; 2017.

43. Yannou B. Supporting need seeker innovation: the Radical Innovation Design methodology. In: DS 80-8 Proceedings of the 20th International Conference on Engineering Design. Milano, Italy: The Design Society; 2015. p. 51-60.

44. Seepersad CC, Pedersen K, Emblemsvåg J, Bailey R, Allen JK, Mistree F. The Validation Square: How Does One Verify and Validate a Design Method? In: Lewis KE, Chen W, Schmidt LC, editors. Decision Making in Engineering Design [Internet]. New York, NY: ASME; 2006 [cited 2017 Aug 22]. Available from: http://dx.doi.org/10.1115/1.802469.ch25 
45. Bekhradi A, Yannou B, Cluzel F. Importance of Problem Setting Before Developing a Business Model Canvas. In: DS 84: Proceedings of the DESIGN 2016 International Design Conference. Cavtat, Dubrovnik, Croatia: Design Society; 2016. p. 907-16.

46. Crocherie G, Rognon N, Guigon M, Casert P, Terreaux Z, Taqi S, et al. Dental Imaging of Tomorrow - Course SE 2200 CIPS 2015 Report. Châtenay-Malabry, France: CentraleSupélec; 2015 Dec p. 102.

47. Parmee RJ, Collins CM, Milne WI, Cole MT. X-ray generation using carbon nanotubes. Nano Converg. 2015 Dec;2(1).

48. Yannou B, Yvars P-A, Hoyle C, Chen W. Set-based design by simulation of usage scenario coverage. J Eng Des. 2013 Mar 21;24(8):575-603.

49. Yannou B, Zimmer B, Farel R, Jankovic M, Stal-Le Cardinal J. Proofs of utility, innovation, profitability and concept for innovation selection. In: DS 75-9: Proceedings of the 19th International Conference on Engineering Design (ICED13), Design for Harmonies. Seoul, Korea: The Design Society; 2013. p. 377-88.

50. Yannou B, Farel R, Cluzel F, Bekhradi A, Zimmer B. The UNPC innovativeness set of indicators for idea or project selection and maturation in healthcare. Int J Des Creat Innov. 2016 Mar 23;1-17. 
Lamé, Guillaume, Bernard Yannou, and François Cluzel. 2017. "Usage-driven problem design for radical innovation in healthcare." BMJ Innovations (in press). doi: 10.1136/bmjinnov-2016-000149. 